\title{
Circulación de teatro y diplomacia cultural en el Río de la Plata
}

\author{
Theater and cultural diplomacy in the Río de la Plata
}

\author{
Raúl Santiago Algán raul.algan@gmail.com
}

https://orcid.org/0000-0001-8659-0889

Universidad Argentina de la Empresa; Instituto de Ciencias Sociales y Disciplinas Proyectuales/

Consejo Nacional de Investigaciones Científicas y Técnicas, Argentina

Resumen

La cultura, entendida como pilar para el desarrollo de los Estados, además de un motor de crecimiento es una forma de vincularse con otras naciones. En este sentido, el arte materializa la cultura a través de sus lenguajes. De ellos, el escénico es el que mejor populariza la identidad cultural de quienes habitan el Río de la Plata hacia el exterior. El objetivo principal de esta ponencia es analizar la circulación teatral entre la Ciudad de Buenos Aires y Montevideo. El objetivo secundario, mensurar esa circulación para poder cuantificarla. 
Se propone abordar la problemática circunscribiendo el análisis a 2010-2017 puesto que es el período en que se produjo la profundización ideológica en ambos países de gobiernos de centroizquierda y parte del cambio de gobiernos. De este modo, se podrá observar, a través de la obtención de indicadores y el análisis de contenido de algunos tratados y acuerdos puntuales que se han suscripto entre los Estados así como la circulación teatral en términos cuantitativos. De esta manera, al comprender la circulación de teatro y la diplomacia cultural como variables, se procura relevar si en la práctica se genera el ámbito propicio para poder concebir una diplomacia cultural conjunta entre ambas ciudades. Asimismo, se espera analizar la incidencia de la denominada diplomacia cultural en la circulación teatral entre ambas ciudades. Profesionalmente, se observan casos de estudio interesantes, como la Movida Teatral de las dos Orillas o el Corredor Latinoamericano de Teatro, como ejemplos de esta acción cultural. No obstante, queda por ver en qué medida las políticas culturales de los gobiernos locales incentivan este tipo de prácticas. Por lo tanto, se busca encontrar el vínculo entre praxis y relaciones interculturales a una pequeña escala (ciudad-ciudad) para analizarlas.

Palabras Clave: diplomacia cultural; gestión cultural; cooperación cultural internacional; artes escénicas.

\section{Abstract}

Culture understood as a pillar for the development of states, as well as a growth engine, is a way of linking with other nations. In this sense, art materializes culture through its languages. Of these, the scenic is the one that best popularizes the cultural identity of those who inhabit the Río de la Plata abroad. The main objective of this paper is to analyze the theatrical circulation between the City of Buenos Aires and Montevideo. The secondary objective, to measure that circulation to be able to quantify it.

It is proposed to address the problem circumscribing the analysis to 2010-2017 since it is the period in which the ideological deepening took place in both countries of centre-left governments and part of the change of governments. In this way, it will be possible to observe, through the obtaining of indicators and the analysis of the content of some treaties and specific agreements that have been signed between the States as well as the theatrical circulation in quantitative terms.

In this way, when understanding the circulation of theatre and cultural diplomacy as variables, it is sought to highlight whether in practice the enabling environment is generated to be able to 
conceive joint cultural diplomacy between both cities. Likewise, it is expected to analyze the incidence of the so-called cultural diplomacy in the theatrical circulation between both cities. Professionally, interesting case studies are observed, such as the Theatrical Move of the Two Banks or the Latin American Theater Corridor, as examples of this cultural action. However, it remains to be seen to what extent the cultural policies of local governments encourage this type of practice. Therefore, we seek to find the link between praxis and intercultural relationships on a small scale (city-city) to analyze them.

Keywords: cultural diplamacy; cultural management; international cultural cooperation; performing arts.

\section{Fundamentación del problema}

Buenos Aires y Montevideo son ciudades que han nacido hermanadas en la clandestinidad. Su origen, incubado en oposición al poderío formal del Alto Perú y de la, por entonces extensa, provincia virreinal de Tucumán y la Docta Córdoba, estuvo marcado por el contrabando, la economía vinculada al mercado negro y el poder informal. Hermanadas en la clandestinidad, también han sido férreas rivales ya que la competencia entre ambas supo ser de tal calibre que

el consulado porteño (es decir, la reunión de los comerciantes porteños) se opuso en 1804 a que se construyese un faro en el puerto oriental. Las tensas relaciones entre ambas ciudades explican también por qué Montevideo fue luego uno de los baluartes realistas contra la Revolución de Mayo (Felix Luna, 2000, p. 23).

Justamente, a raíz de los procesos de reconquista y expulsión de los ingleses a principios del siglo XIX, es que las ciudades fueron, progresivamente, dejando esa rivalidad comercial. Valga recordar la identidad cultural que subyacía en estos territorios para no incurrir en anacronismos pues «en 1806 éramos todos españoles, y como tales reaccionamos frente al invasor británico, así fue como la sociedad de ambas orillas, fervorosamente católica, veía en aquella presencia la irrupción del temido hereje protestante» (Julio María Sanguinetti, 2006). En este contexto, la trascendencia de la participación de Montevideo en la campaña de expulsión de los ingleses del territorio porteño le valió el título de muy fiel y reconquistadora ciudad de San Felipe y Santiago otorgado por la corona española. Pero es dable recordar que «de estos episodios surge nítidamente lo que era la comunidad de destino de estas dos ciudades, emparentadas de 
mil modos, pese a la natural rivalidad portuaria que ya venía de atrás y que generaba en sus comerciantes enfrentamientos constantes» (Sanguinetti, 2006). En este sentido, se configuraría en los albores del siglo XIX una identidad cultural que erosionará, durante todo el proceso de la conformación de los Estados nación que hoy reconocemos como República Oriental del Uruguay y República Argentina, el nosotros contra ellos, volviendo la geografía un total integrado de prácticas culturales compartidas.

Así, para finales del siglo XIX, nos encontramos con que ambas ciudades ya están configuradas en el marco de una estructura organizativa relativamente ajustada a los parámetros de las metrópolis modernas. Ambas, próximas a los festejos de los centenarios de sus respectivos países, cuentan con estructuras culturales que funcionan como sendas de doble vía.

En lo que atañe a la circulación de las artes escénicas por la cuenca del Río de la Plata, el circo criollo es clave para comprender las relaciones culturales internacionales que ambas ciudades han sabido forjar. $Y$ es que el circo criollo, génesis de la teatralidad del Río de la Plata, es una «creación argentino-uruguaya [y] está relacionado íntimamente con nuestra identidad latinoamericana” (Isabel Croce, 2012, p. 8). La circulación de este arte trashumante ha servido a los gobiernos conservadores como factor cultural de asentamiento de las nuevas nacionalidades. Detrás de la conquista de un territorio expropiado a pueblos originarios se extendía el ferrocarril como símbolo de una economía agroexportadora y, en torno a él, se asentaba un caserío o ciudad incipiente. Pues bien, mientras esto iba sucediendo, el circo ganaba los caminos llevando consigo el espíritu de una cultura criolla que respondía a la necesidad del gobierno de asentar, simbólicamente, el ser nacional.

Así es como el teatro, manifestado en el circo criollo, se postula como una forma incipiente de diplomacia cultural. Por esta, en principio se entiende «la política exterior de un Estado hacia otros, pueblo y naciones, sobre la base de la cooperación (...) como una modalidad o tarea de sus relaciones internacionales» (Daniel Camacho \& Jaime Delgado, 2011, p. 23). En el marco de estas relaciones internacionales se insertan los mecanismos diplomáticos y de cooperación que abordaremos en la presente ponencia, así como su vínculo con la circulación teatral.

Nuestra propia historia como humanidad está teñida de intercambios y relaciones porque, como bien ha definido la antropología en su recorrido histórico, no hay identidad sin alteridad. Es decir que no es posible definirse como argentinos, uruguayos o peruanos si del otro lado no hay chilenos, brasileños o bolivianos que reconozcan los rasgos identitarios propios y de otros. En este sentido, la historia de la humanidad está hecha de intercambios, mal que les pese a muchos teóricos de la pureza. Es, entonces, en este sentido que los Estados se encuentran 
con la necesidad de intervenir para facilitar estas relaciones. Lo que está por verse es si esa intervención influye de manera positiva o negativa.

La dificultad de abordar los vínculos culturales desde las relaciones internacionales como disciplina de enfoque es que la cultura, manifestada en las artes escénicas como lenguaje catalizador, es una actividad practicada antes que teorizada. Como sostiene Norberto Bobbio (2010), «la expresión relaciones internacionales indica en los términos más generales el conjunto de las relaciones entre los Estados, entendidos ya sea como aparato que como comunidad» (p. 1369). Por tanto, las relaciones internacionales se circunscriben, en principio, a las acciones que los Estados desarrollan para otros de las fronteras territoriales hacia afuera. Pero no sólo los Estados intervienen como agentes de las relaciones internacionales, también lo hacen los organismos internacionales y, en el caso específico de la cultura, los agentes culturales. En este sentido, una cuestión clave es dirimir el enfoque con que se ve la cultura en el marco de las relaciones internacionales.

La cultura en términos generales es un concepto muy difícil de determinar puesto que en sí mismo es ambiguo. Una primera aproximación puede ser recuperada en virtud de una reciente definición propuesta por Terry Eagleton (2017) al pensarla en función de cuatro macrosignificados que abordan lo intelectual y artístico, el desarrollo espiritual, los valores, costumbres y creencias o la forma de vida en su conjunto. Dada esta característica es que se utilizan estos enfoques para poder ajustar los abordajes que se hace sobre la materia. Sin ánimos de caer en reduccionismos, se pueden identificar dos enfoques: uno antropológico y uno económico. El primero concibe la cultura como una totalidad compleja, que comprende la forma de ser, el conocimiento, las creencias, la forma de comportarse, leyes, es decir todo aquello que el hombre ha incorporado como parte de la sociedad. En el segundo enfoque se puede ver como la cultura, a través de los bienes y servicios que crean sus agentes, genera un valor agregado a las economías. Es decir que se entiende a la cultura en virtud de ciertas actividades emprendidas por las personas y los productos de dichas actividades, que tienen que ver con los aspectos intelectuales y artísticos de la vida humana (Marco Aime, 2015).

Para las relaciones internacionales la cultura debe ser comprendida como el conjunto de ambas, puesto que permite a los Estados, a través de sus embajadas, hacer una proyección cultural exterior de sus artistas pero también potenciar los vínculos comerciales y los negocios. Dentro de este marco, se comprende a la diplomacia cultural en los términos que propone Claudio Giacomino (2009) al caracterizarla como la interrelación de cuatro áreas temáticas. Estas son la política y la estrategia externa de los estados, la cooperación cultural, la integración y la difusión. En la segunda área temática corresponde hacer una aclaración: para que haya cooperación debe haber un proceso de ida y vuelta entre los Estados o ciudades 
cooperantes, si no lo hay, la diplomacia cultural es solo proyección cultural exterior. En la tercera área, que es la que interesa, los mecanismos de integración se dan en torno a entidades supranacionales que marcan la agenda política de la región pero también en función de los tratados y convenios como lo que se analizan en la presente ponencia.

Corresponde hacer una mención, aunque breve, sobre la aplicación de las nociones vinculadas a las relaciones internacionales aplicadas a la escala subnacional o descentralizada. En este sentido no es habitual que los Estados deleguen en ciudades acciones de diplomacia cultural o de cooperación cultural internacional. No obstante, en la práctica, se observan que, en el ámbito de la cultura y de las artes escénicas muchas organizaciones privadas se ocupan de fomentar los lazos entre las teatralidades de países vecinos. Tal es el caso de la Movida Teatral de las dos Orillas que se autodefine como un intercambio artístico. Lo interesante de este caso de estudio, que por cuestiones de espacio excede la presente ponencia, es que recibe financiamiento parcial de los Estados. Así, el motor de la actividad es enteramente privada pero los resultados de su accionar redundan en materia de diplomacia cultural porque genera un vinculo más rico entre las ciudades. Si hubiera una acción empírica orientada a la integración cultural, esta sería un ejemplo cabal.

Dentro de esta concepción, las artes escénicas cumplen la doble función de comunicar y exponer las prácticas culturales en otros mercados y generar posibilidades comerciales a través de su lenguaje y su identidad cultural. En este sentido el escenario como dispositivo es clave puesto que «el hecho teatral no puede definirse fundamentalmente por el actor, ni mucho menos por el texto dramático. Pero el hecho teatral sí queda definido por el ámbito escénico» (Gastón Breyer, 1968, p. 54).

Recordemos que cuando se habla de teatro como representación escénica nunca se refiriere al texto dramático en sí mismo. Ni el mercado ni sus agentes tienen injerencia en la escritura dramática, porque ella le concierne exclusivamente al dramaturgo, compositor o coreógrafo. Por eso la sala como espacio de representación es condicionante de la recepción, porque es el lugar en donde se reúnen al mismo tiempo la fuerza oferente y la fuerza demandante. En otras palabras, sólo hay hecho teatral cuando el espectador ocupa la platea y el artista el escenario. Esa condición de efímero hace que el teatro se mantenga a lo largo del tiempo como práctica cultural estable en Occidente. La originalidad de cada representación, que la hace única e imposible de serializar, dota al teatro de un rasgo imposible de suplantar.

Por esa razón, es un error sostener que el teatro se distribuye. En su lugar, lo correcto es decir que el teatro circula porque por ser cada función única, es imposible distribuirla. Es cierto que hay concepciones de representación o explotación diferentes en cada país y que eso responde a la idiosincrasia de cada uno. Por ejemplo, en Buenos Aires, una obra de teatro montada en 
relación de dependencia muy improbablemente cambie de sala en los primeros meses posteriores a su estreno. En España, en cambio, la rotación es mucho más ágil, lo que impide que la obra pueda instalarse definitivamente en cartel y posicionarse como oferta. Por eso, el rol del distribuidor, que va de feria en feria procurando vender las obras de su cartera, es tan común en el país ibérico.

Entonces se comprende la circulación teatral como posible factor que configura las relaciones internacionales $\mathrm{o}$, al menos, el planteamiento que los políticos y funcionarios hacen sobre ella. En este sentido, cabe mencionar que la internacionalización de las artes escénicas es un campo fértil que aún no ha alcanzado su potencial en nuestro territorio. Como sostiene Federico Irazábal, actual director del Festival Internacional de Teatro de Buenos Aires (FIBA), el teatro (sobre todo el denominado independiente o alternativo) «empezó a utilizar esa lógica del productor como un modo de organización de los materiales desde el punto de vista específico de la producción. Lo que nunca ocurrió es el reconocimiento de la necesidad de un agente de internacionalización» (Federico Irazábal, comunicación personal, marzo de 2019). Es decir que esta es un tipo de actividad que se desarrolla sin que existan ámbitos formales de educación donde los agentes culturales puedan potenciar su perfil y profesionalizar su labor.

Así, si la cultura es abordada desde los dos enfoques, siendo las artes escénicas el lenguaje artístico que la condensa y siendo así entendida desde las relaciones internacionales, ¿qué carga valorativa tiene para los Estados? Es decir, ¿por qué las administraciones públicas encauzarían esfuerzos en favor de comunicar su cultura? Para comprender esta cuestión debemos contextualizar los paradigmas clásicos de las relaciones internacionales y comprender cómo se enmarca en estos la circulación teatral.

Siguiendo la línea teórica de Claudia Jiménez González (2004), se pueden reconocer tres grandes paradigmas desde los cuales concebir las relaciones internacionales. Por un lado, una visión de corte realista. En esta, las relaciones internacionales son concebidas en un marco caótico y de tensión de fuerzas en el que predomina el Estado que logra imponerse a los demás.

Para el segundo paradigma, que responde al nombre de idealista, el hombre es concebido como un ser social y político, en el más puro sentido aristotélico. Así, para los idealistas, el principal objetivo será la persecución de la paz. Esta idea es retomada a mediados de la década del cincuenta por los liberales y su formulación más común, que es la necesidad de la cooperación entre Estados con el fin de evitar guerras. Esta concepción, por ejemplo, se refleja en la Declaración de 1966 de la Unesco al reafirmar que «las guerras nacen en la mente de los hombres, [y] es en la mente de los hombres donde deben erigirse los baluartes de la paz» (Unesco, 1966, segundo párrafo).

Question, Vol. 1, N. ${ }^{\circ}$ 65, abril 2020. ISSN 1669-6581

Instituto de Investigaciones en Comunicación | Facultad de Periodismo y Comunicación Social | Universidad Nacional de La Plata La Plata | Buenos Aires | Argentina

Página 7 de 17 
Por último, un tercer paradigma ingresa en escena para cuestionar todo lo anterior: el paradigma marxista. Para esta corriente, «la libre competencia es precisamente el principal determinante del conflicto internacional» (Jiménez González, 2004, p. 126). Este conflicto internacional estará signado por la supervivencia, que empuja a los Estados a intentar imponerse unos sobre otros. Sin embargo, se separa en este punto de la corriente realista al virar el control del poder del Estado a la clase dominante: es la clase social y no el Estado el actor clave de las relaciones internacionales. Por lo tanto, los Estados son instituciones al servicio de la burguesía.

Con posterioridad, surgen nuevas visiones respecto de las relaciones internacionales. Una de ellas, particularmente interesante a los fines de esta investigación, es el neoinstitucionalismo. Esto es así puesto que vuelve a situar al Estado como núcleo de la política mundial pero también da lugar a los agentes no estatales a tener una participación activa en las acciones vinculadas a la gestión cultural. Estos, en el caso particular de la cultura, son reconocidos por Javier Brun, Joaquín Tejero, y Pedro Canut Ledo (2008) como redes culturales definidas como «un grupo de individuos en el que todos asumen responsabilidades para conseguir objetivos compartidos» (p. 79). Mientras que esta teoría pone el acento en la institución, la teoría constructivista, por su parte, enfatiza la relación entre los agentes: «Para el análisis constructivista, el fenómeno de la cooperación se concentra en la manera en que las prácticas intersubjetivas entre los actores se convierten en identidades e intereses forjados por la interacción» (Jiménez González, 2004, p. 138). Así, se observa como las estructuras se organizan en torno a las acciones concretas, puesto que es a través de la interacción recíproca que se crean estructuras sociales estables en las cuales se definen las identidades.

\section{Metodología}

Esta investigación es un primer acercamiento al abordaje del vínculo entre las relaciones culturales internacionales de los Estados miembros de Mercosur y la circulación teatral entre sus ciudades. Como tal, forma parte de un proyecto más amplio que se enmarca en una tesis doctoral, cuyo objetivo fundamental es abordar la relación entre los instrumentos de cooperación internacional y la circulación de teatro. El enfoque de esta ponencia es mixto, puesto que es necesario explorar el fenómeno en su conjunto debido a que la información disponible es parcial y está repartida en fuentes diversas. Adicionalmente se describen las variables y su comportamiento. Así, dada la escasa información que hay respecto de la circulación teatral en la cuenca del Río de la Plata, consideramos a este estudio de tipo exploratorio y descriptivo.

Question, Vol. 1, N. ${ }^{\circ}$ 65, abril 2020. ISSN 1669-6581

Instituto de Investigaciones en Comunicación | Facultad de Periodismo y Comunicación Social | Universidad Nacional de La Plata La Plata | Buenos Aires | Argentina

Página 8 de 17 
En todo el trabajo puede referirse, como estrategia metodológica, la investigación documental, puesto que se ha intentado rastrear en los tratados y en la información empírica indicios de mutuo condicionamiento a través de documentos y testimonios. No obstante, dado que esta ponencia se enmarca en un proyecto de investigación doctoral se considera que a futuro este trabajo puede ser base de un análisis más profundo.

Las principales fuentes de consulta han sido las áreas de análisis estadístico del Gobierno argentino y del Gobierno de la Ciudad de Buenos Aires. Ellas son, respectivamente, el Sistema de Información Cultural de la Argentina (Sinca) y Data Cultura. De estas fuentes se obtuvo la información empírica referida a las obras de teatro que han circulado entre las ciudades. Entre 2010 y 2017 se han relevado 698 obras de teatro, de las cuales 616 fueron argentinas y 82 uruguayas. En todos los casos, no se discrimina por obra repetida año a año, porque la unidad de medida es la gira y sus consecuentes representaciones. Para tomar la muestra, en este sentido, se tuvieron en consideración los siguientes requisitos.

Por un lado, que se considera obra de teatro el texto dramático montado y funcionando en un dispositivo escénico con su correspondiente diseño de producción, arte, actuación y espectadores. Por el otro, que las obras representadas en Montevideo debieron ser escritas, con carácter de exclusividad, por dramaturgos argentinos mientras que las representadas en la Ciudad de Buenos Aires, por dramaturgos uruguayos.

Siguiendo estos dos criterios de selección se solicitó a las fuentes referidas la información. Vale aclarar en este punto que el Gobierno de la República Oriental del Uruguay no lleva indicadores de consumos y prácticas culturales que pudieran servir a esta investigación. También, que los organismos de gestión colectiva, esto es Argentores por Argentina y la Asociación General de Autores del Uruguay (AGADU) por Uruguay, teniendo en su poder la información, no la socializan para que puedan llevarse adelante investigaciones de estas características.

Respecto a la segunda variable analítica, esto es los documentos bilaterales o multilaterales que representan las diferentes instancias de diplomacia y cooperación cultural, la principal fuente fue la biblioteca digital de tratados de la Cancillería del Gobierno argentino. En este sentido, se han relevado diez documentos que condensan las relaciones culturales internacionales de los países analizados, siendo tres de ellos de escala nacional y el resto de escala ciudad. Asimismo, para lo que se refiere a instituciones multinacionales a las que pertenecen ambas ciudades, la fuente ha sido Mercociudades y Ciudades y Gobiernos Locales Unidos (CGLU), entre otras, porque comprendemos que aquí se da la escala de relaciones internacionales de tipo subnacional o descentralizada como la que estamos construyendo en esta ponencia.

Question, Vol. 1, N. ${ }^{\circ}$ 65, abril 2020. ISSN 1669-6581

Instituto de Investigaciones en Comunicación | Facultad de Periodismo y Comunicación Social | Universidad Nacional de La Plata La Plata | Buenos Aires | Argentina

Página 9 de 17 


\section{Resultados y discusión}

Las variables involucradas en esta ponencia son la circulación teatral y la diplomacia cultural. Dado que la primera se materializa en aquellas obras de autor, autora o autores de una nacionalidad que fueran representadas en la capital del país vecino y viceversa, se han relevado las obras que, respondiendo a estas características, hayan circulado en el período que analizamos, en el país vecino y viceversa. En el caso de la segunda, materializada en convenios y acuerdos, se analizó las temáticas recurrentes con el objeto de obtener un sistema de categorías funcional a este análisis.

Conforme a la información suministrada por el Ministerio de Cultura de la Ciudad Autónoma de Buenos Aires, en el período que estamos analizando hubo un intercambio fluido y constante, aunque dispar, de teatro entre ambas ciudades. En la Figura 1 se muestra la cantidad de obras teatrales argentinas representadas en Montevideo, así como las uruguayas representadas en Buenos Aires.

\begin{tabular}{ccc}
\hline \hline Año & Argentinas en Montevideo & Uruguayas en Buenos Aires \\
\hline 2010 & 60 & 2 \\
2011 & 79 & 6 \\
2012 & 65 & 6 \\
2013 & 65 & 10 \\
2014 & 90 & 15 \\
2015 & 84 & 9 \\
2016 & 87 & 14 \\
2017 & 86 & 20 \\
Total & 616 & 82
\end{tabular}

Figura 1. Obras que circularon entre Montevideo y Buenos Aires en el período 2010-2017 (Fuente: Elaboración propia a partir de información suministrada por el Ministerio de Cultura de la Ciudad de Buenos Aires)

En este sentido, de acuerdo con la fuente, en todos los casos se trata de obras en giras y/o de obras cuyo autor es argentino pero cuyo elenco es uruguayo. Si bien está por fuera del recorte temporal que se propone corresponde mencionar que la Dirección Nacional de Asuntos Culturales dependiente del Ministerio de Relaciones y Culto informa haber colaborado con tres obras en 2018 y dos en 2019. 
Por su parte, en lo que atañe a la segunda variable de análisis, se han identificado diversos instrumentos legales, siendo la mayoría convenios que encuentran su génesis en un acuerdo de 1975 suscripto por ambos Estados, lo cual habla de una impronta de cooperación cultural centralizada, mientras que los documentos firmados entre las ciudades son convenios. Como antecedente directo de estas relaciones culturales internacionales, se observa un convenio firmado en 1957, extinto con el acuerdo que mencionamos de 1975. El hito que vira de uno a otro es que Unesco, en 1966, emite su Declaración de los Principios de la Cooperación Cultural Internacional de la cual ya hemos hablado. En resumen, se ha relevado la siguiente información:

\begin{tabular}{|c|c|c|c|c|}
\hline Firma & Duración & Escala & $\begin{array}{l}\text { Tipo de } \\
\text { acuerdo }\end{array}$ & "Denominación \\
\hline $27 / 4 / 1957$ & $\begin{array}{c}\begin{array}{c}\text { Extinguido } \\
\text { el }\end{array} \\
30 / 07 / 1975\end{array}$ & $\begin{array}{c}\text { E/ } \\
\text { Estados }\end{array}$ & Convenio & $\begin{array}{c}\text { Convenio Cultural entre la Rep. } \\
\text { Argentina y la Rep. Oriental del } \\
\text { Uruguay }\end{array}$ \\
\hline 30/12/1975 & Vigente & $\begin{array}{c}\text { E/ } \\
\text { Estados }\end{array}$ & Acuerdo & $\begin{array}{l}\text { Acuerdo de Coop. Cultural entre el } \\
\text { Gob. de la Rep. Argentina y el } \\
\text { Gob. de la Rep. Oriental del } \\
\text { Uruguay }\end{array}$ \\
\hline $4 / 11 / 1996$ & Vigente & $\begin{array}{c}\text { E/ } \\
\text { Ciudades }\end{array}$ & $\begin{array}{l}\text { Convenio } \\
13 / 96\end{array}$ & $\begin{array}{l}\text { Declaración Marco sobre Coop. } \\
\text { entre el Gob. de la Ciudad de } \\
\text { Buenos Aires y la Int. Municipal de } \\
\text { Montevideo }\end{array}$ \\
\hline 16/3/1998 & Vigente & $\begin{array}{c}\text { E/ } \\
\text { Estados }\end{array}$ & Convenio & $\begin{array}{c}\text { Convenio de Coop. Cultural entre } \\
\text { la Rep. Argentina y la Rep. } \\
\text { Oriental del Uruguay }\end{array}$ \\
\hline $16 / 12 / 2007$ & Vigente & $\begin{array}{c}\text { E/ } \\
\text { Ciudades }\end{array}$ & $\begin{array}{l}\text { Convenio } \\
01 / 08\end{array}$ & $\begin{array}{l}\text { Convenio Marco de Coop. entre la } \\
\text { Int. Municipal de Montevideo y el } \\
\text { Gob. de la Ciudad de Buenos } \\
\text { Aires }\end{array}$ \\
\hline $8 / 7 / 2010$ & Vigente & $\begin{array}{c}\text { E/ } \\
\text { Ciudades }\end{array}$ & $\begin{array}{l}\text { Convenio } \\
21 / 10\end{array}$ & $\begin{array}{l}\text { Convenio Marco de Coop. y } \\
\text { Colaboración entre el Gob. de la } \\
\text { Ciudad de Buenos Aires y el } \\
\text { Ministerio de Educación y Cultura }\end{array}$ \\
\hline \multicolumn{5}{|c|}{ Question, Vol. 1, N.º 65, abril 2020. ISSN 1669-6581 } \\
\hline Instituto de Inve & tiones en Comu & $\begin{array}{l}\text { ción | Facultad } \\
\qquad \text { La Plata | }\end{array}$ & $\begin{array}{l}\text { eriodismo y Cor } \\
\text { nos Aires | Ars } \\
\text { na } 11 \text { de } 17\end{array}$ & $\begin{array}{l}\text { unicación Social | Universidad Nacional de La Plata } \\
\text { ntina }\end{array}$ \\
\hline
\end{tabular}


de la Rep. Oriental del Uruguay

9/12/2011 Vigente

$\mathrm{E} /$

Ciudades

\section{Convenio}

$16 / 11$
Convenio Marco de Coop. entre la Int. Municipal de Montevideo y el

Gob. de la Ciudad de Buenos

Aires

Figura 2. Relevamiento de acuerdos entre países y ciudades. (Fuente: elaboración propia a partir de información suministrada por la biblioteca general de tratados de la Cancillería argentina y la Legislatura de la Ciudad Autónoma de Buenos Aires.

Cabe mencionar, ya que estamos relevando las relaciones culturales entre los países y las ciudades en particular, que en 1975 se declara a la ciudad de Montevideo hermana de Buenos Aires por Res. 32.524. También que en 2003 se firma una carta de intención entre las autoridades de las ciudades con objeto de promocionar actividades turísticas.

Para complementar este análisis, realizamos un relevamiento de las temáticas que aparecen mencionadas en los documentos, arribando al siguiente resultado:

\begin{tabular}{|c|c|c|c|}
\hline Firma & Escala & Denominación & Materias \\
\hline $27 / 4 / 1957$ & $\begin{array}{c}\text { E/ } \\
\text { Estados }\end{array}$ & $\begin{array}{c}\text { Convenio Cultural entre la } \\
\text { Rep. Argentina y la Rep. } \\
\text { Oriental del Uruguay }\end{array}$ & $\begin{array}{c}\text { Arte. Becas. Capacitación. } \\
\text { Cinematografía. Comisión Mixta } \\
\text { Cooperación Cultura, Ciencia y } \\
\text { Técnica. Seminarios. Deporte. } \\
\text { Educación. Música. }\end{array}$ \\
\hline 30/12/1975 & $\begin{array}{c}\text { E/ } \\
\text { Estados }\end{array}$ & $\begin{array}{l}\text { Acuerdo de Coop. Cultural } \\
\text { entre el Gob. de la Rep. } \\
\text { Argentina y el Gob. de la } \\
\text { Rep. Oriental del Uruguay }\end{array}$ & $\begin{array}{l}\text { Arte. Cinematografía. } \\
\text { Cooperación Cultura, Ciencia y } \\
\text { Técnica. Cursos y seminarios. } \\
\text { Educación. Intercambio de } \\
\text { expertos. Música. Publicaciones. }\end{array}$ \\
\hline
\end{tabular}

Teatro. 


\begin{tabular}{|c|c|c|c|}
\hline 4/11/1996 & $\begin{array}{c}\text { E/ } \\
\text { Ciudades }\end{array}$ & $\begin{array}{l}\text { Declaración Marco sobre } \\
\text { Coop. entre el Gob. de la }\end{array}$ & $\begin{array}{c}\text { Gestión Urbana. Educación y } \\
\text { Cultura. Relaciones }\end{array}$ \\
\hline & & $\begin{array}{c}\text { Ciudad de Buenos Aires y } \\
\text { la Int. Municipal de } \\
\text { Montevideo }\end{array}$ & Internacionales. Turismo. Deporte \\
\hline $16 / 3 / 1998$ & $\begin{array}{c}\text { E/ } \\
\text { Estados }\end{array}$ & $\begin{array}{l}\text { Convenio de Coop. } \\
\text { Cultural entre la Rep. } \\
\text { Argentina y la Rep. } \\
\text { Oriental del Uruguay }\end{array}$ & $\begin{array}{c}\text { Arte. Bienes Culturales. } \\
\text { Cinematografía. Comisión Mixta } \\
\text { Cooperación Cultura, Ciencia. } \\
\text { Deporte. Música. Propiedad } \\
\text { intelectual. Publicidad. Teatro. }\end{array}$ \\
\hline 16/12/2007 & $\begin{array}{c}\text { E/ } \\
\text { Ciudades }\end{array}$ & $\begin{array}{l}\text { Convenio Marco de Coop. } \\
\text { entre la Int. Municipal de } \\
\text { Montevideo y el Gob. de la } \\
\text { Ciudad de Buenos Aires }\end{array}$ & $\begin{array}{l}\text { Integración Regional. } \\
\text { Comunicación. Gestión Local. } \\
\text { Educación y Cultura (intercambio } \\
\text { cultural). Teatro. }\end{array}$ \\
\hline 8/7/2010 & $\begin{array}{c}\text { E/ } \\
\text { Ciudades }\end{array}$ & $\begin{array}{l}\text { Convenio Marco de Coop. } \\
\text { y Colaboración entre el } \\
\text { Gob. de la Ciudad de Bs. } \\
\text { As. } \\
\text { y el Ministerio de } \\
\text { Educación y Cultura de la } \\
\text { Rep. del Uruguay }\end{array}$ & $\begin{array}{l}\text { Investigación. Educación. } \\
\text { Promoción. }\end{array}$ \\
\hline $9 / 12 / 2011$ & $\begin{array}{c}\text { E/ } \\
\text { Ciudades }\end{array}$ & $\begin{array}{l}\text { Convenio Marco de Coop. } \\
\text { entre la Int. Municipal de } \\
\text { Montevideo y el Gob. de la } \\
\text { Ciudad de Buenos Aires }\end{array}$ & $\begin{array}{l}\text { Cultura. Turismo. Salud. Medio } \\
\text { Ambiente. Educación. Desarrollo } \\
\text { Urbano e Infraestructura. Política } \\
\text { Internacional. }\end{array}$ \\
\hline
\end{tabular}

Figura 3. Temáticas recurrentes en el relevamiento de los acuerdos. (Fuente: Elaboración propia a partir de información suministrada por la biblioteca general de tratados de la Cancillería Argentina y la Legislatura de la Ciudad Autónoma de Buenos Aires.)

En el relevamiento se observa una preeminencia de los términos cultura y arte. Dentro de este último, sólo se observa que el término teatro aparece mencionado en los acuerdos de 1975, 1998 y 2007, siendo sólo el último entre Ciudad de Buenos Aires y Montevideo. No obstante, 
se entiende que estos acuerdos deberían funcionar como marco para las acciones en conjunto realizadas por los Estados.

En virtud de la información recabada sobre diplomacia cultural y sus instrumentos, así como sobre la circulación teatral y las obras puntuales que han girado entre 2010 y 2017, se observa que no hay una correlación entre lo que postulan los documentos y lo que sucede en la práctica. El enfoque original de esta investigación, es decir, sostener que la circulación teatral es una forma empírica sobre la que se pueden construir relaciones culturales no es condición necesaria ni excluyente para que esto suceda.

En primera instancia, no se observa que la circulación teatral sea equitativa ni equilibrada entre los países ni las ciudades con convenios marco de cooperación. Aquí es donde se pone en evidencia que los postulados del proceso de integración regional no se cumplen. Sostenemos esto porque ambas ciudades pertenecen a organismos internacionales como CGLU, Mercociudades o Ciudades Capitales Iberoamericanas que se supone tienen por objeto reducir desigualdades y plantear escenarios globales más equitativos. Si, por citar un ejemplo, la razón de ser de Mercosur Cultural, programa específico aplicado al campo de la cultura de Mercosur, implementara acciones reales vinculadas a su propósito, la disparidad de obras circulando entre las ciudades analizadas no sería tan grande. En la propia página web del programa queda claro que la Reunión de Ministros de Cultura "tiene por función promover la difusión y conocimiento de los valores y tradiciones culturales de los Estados Parte del MERCOSUR" (Mercosur Cultural, s.f.). No obstante, estos objetivos no se ven reflejados en la dinámica del intercambio cultural entre Montevideo y Buenos Aires.

Con relación a los tratados relevados, la mayoría incluye fórmulas que hacen referencia a la obligación que adquiere cada Estado de difundir la identidad cultural del otro. Cabal ejemplo de esto es el primer artículo del Acuerdo de Cooperación Cultural firmado en 1975 que hace referencia a que cada parte «estimulará el conocimiento de la cultura del otro país y procurará facilitar la acción que desarrollen las instituciones dedicadas a la difusión de los valores culturales y artísticos del mismo» (Acuerdo de Cooperación Cultural entre el Gobierno de la República Argentina y el Gobierno de la República Oriental del Uruguay, 1975). Lo mencionamos como ejemplo cabal porque este documento es constantemente referido en los acuerdos posteriores.

Como puede observarse, los temas recurrentes en los convenios son cultura, educación y arte. Esto, dado lo que mencionáramos en la fundamentación del problema, respecto de lo difícil que es definir cultura y las implicancias de este término no logran construir un espacio real que beneficie la circulación. Es decir que los instrumentos legales que estamos analizando, los cuales se supone que operacionalizan las ideas políticas sobre relaciones culturales 
internacionales, no funcionan como instancia intermedia entre el discurso político y la realidad de los agentes culturales.

En este sentido, llama especialmente la atención la tercera cláusula del Convenio Marco de Cooperación entre la Intendencia Municipal de Montevideo y el Gobierno de la Ciudad de Buenos Aires (2007) porque destaca que en el contexto del intercambio cultural se adoptarán acciones puntuales para hermanar los teatros públicos de ambas ciudades, sobre todo en lo referido a la vinculación entre compañías. Esto no se ve reflejado en los datos empíricos, puesto que gran parte de las obras enviadas de Buenos Aires a Montevideo son del ámbito privado y, de las que han viajado de Montevideo a Buenos Aires, sólo una en 2014 fue representada en un teatro público, el Teatro Nacional Cervantes.

Destaca, en este sentido, la producción independiente o alternativa, lo cual es indicador del fenómeno de precarización laboral que padecen los artistas en ambas orillas del Río de la Plata. Esta afirmación se basa en la proliferación de producciones independientes, esto es de colectivos de artistas reunidos formal o informalmente en torno a un proyecto escénico sin empleador (productor general) y, por lo tanto, sin garantías laborales. En la Argentina, a diferencia de Uruguay, existe la sociedad accidental de trabajo, mejor conocida como cooperativa de actores que, si bien está reconocida por el sindicato argentino de Actores, no reviste ningún formato legal. Por ello, aunque de un lado existe una relativa formalidad, se observa que la precarización es evidente en ambos lados.

En lo que atañe a las dinámicas de los mercados teatrales de ambas ciudades no debe desatenderse una cuestión que influye también en la circulación de las obras. Se refiere puntualmente a la sobre oferta que hay en la Ciudad Autónoma de Buenos Aires que muchas veces inocula propuestas foráneas que se pierden en la nutrida cartelera. Por su parte, Montevideo tiene una producción menos profusa y la penetración cultural de los medios de comunicación argentinos nos es menor. Por esta razón una obra que gira de Buenos Aires a Montevideo tiene, a diferencia de la dinámica inversa, una posibilidad de explotación comercial más grande.

En suma, es importante que los gobiernos locales, dada su escalabilidad, tomen nota de la dificultad que hay para materializar los preceptos de las relaciones culturales internacionales dada la oportunidad que podría representar para el sector de las artes escénicas. En este sentido, la escalabilidad torna más viable las relaciones culturales porque se trata de un territorio más acotado y, al mismo tiempo, el efecto multiplicador que trae aparejada la gira de un espectáculo hace, a su vez, que el beneficio redunde en un impacto positivo en otras economías conexas. En este sentido se observa cómo el ámbito cultural a través de sus agentes comienza a generar un discurso propio vinculado al valor cultural de su actividad. Por 
ello «las dimensiones del valor cultural y los métodos que se podrían utilizar para evaluarlo son cuestiones que se deben originar en su discurso cultural, aun cuando en algún momento fuese posible tomar prestados modos de pensamiento económicos como forma de establecer modelos adecuados» (David Throsby, 2001, p. 41). Si las administraciones públicas se hicieran eco de esta necesidad, encontrarían un universo de artistas dispuestos a invertir tiempo y trabajo en proyectar giras al exterior.

\section{Conclusiones o reflexiones finales}

De esta forma, habiendo relevado la circulación teatral, con la dificultad que supone el acceso a la información, producto de la no sistematización de datos por parte de los gobiernos locales, se ha podido tener una muestra del caudal de obras que giran entre las capitales. Asimismo, un relevamiento documental de los instrumentos de cooperación nos permite comprender, o al menos categorizar, las sucesivas visiones que los gobernantes han tenido sobre las relaciones culturales. Dado que no se han encontrado relaciones causales, al menos en apariencia, entre una variable y otra, queda por definir de qué modo esta brecha puede ser acotada.

Es decir que las relaciones culturales internacionales, la vinculación política y sistemática de los gobiernos en pos de proyectarse culturalmente hacia el exterior y de recibir manifestaciones artísticas no se alinea con la realidad. De este modo, al no hacerlo, deja librada a los intereses particulares de los agentes culturales y al ámbito privado una acción que debiera ser asumida por el Estado, dado que es clave para el posicionamiento geopolítico y la integración regional. Como futura línea de investigación puede ser relevante analizar el mismo modelo de intercambio documental y teatral con otras ciudades capitales de Estados miembros de Mercosur. En este sentido cabría analizar si en la práctica existen corredores o plataformas de circulación estables entre las ciudades que operen con independencia de las voluntades políticas de los gobiernos de turno. Así, podría configurarse las formas de las relaciones culturales internacionales desde un punto de vista descentralizado para corroborar si dicho intercambio es modelizable. 
Referencias bibliográficas

Aime, M. (2015). Cultura. Ciudad Autónoma de Buenos Aires: Adriana Hidalgo Editora.

Bobbio, N. (2010). Diccionario de Política. México D. F., México: Siglo XXI.

Breyer, G. (1968). Teatro: El Ámbito Escénico. Ciudad Autónoma de Buenos Aires: Centro Editor de América Latina.

Brun, J., Tejero, J., \& Canut Ledo, P. (2008). Redes Culturales. Claves para vivir en la globalización. Madrid, España: Aecid.

Camacho, D., \& Delgado, J. (2011). Diplomacia cultural, educación y derechos humanos. México D. F.: Secretaria de Relaciones Exteriores de México.

Croce, I. (2012). Familia de circo. Cuadernos de Picadero, pp. 08-11. Ciudad Autónoma de Buenos Aires, Argentina: INT Ediciones

Eagleton, T. (2017). Cultura. Ciudad Autónoma de Buenos Aires, Argentina: Taurus.

Giacomino, C. A. (2009). Cuestión de imagen. Diplomacia cultural en el siglo XXI: razones y modalidades. Ciudad Autónoma de Buenos Aires, Argentina: Biblos.

Irazábal, F. (abril de 2019). Comunicación personal con Federico Irazábal. Ciudad Autónoma de Buenos Aires.

Jiménez González, C. G. (2003). Las teorías de la cooperación internacional dentro de las relaciones internacionales. Polis, pp. 115-147.

Luna, F. (2000). Breve historia de los argentinos (5 ed.). Ciudad Autónoma de Buenos Aires, Argentina: Planeta de Bolsillo.

Mercosur Cultural. (s.f.). Mercosur Cultural. Recuperado el 15 de septiembre de 2019 de:

http://www.mercosurcultural.org/ .

Sanguinetti, J. M. (11 de agosto de 2006). Historia en dos ciudades. La Nación. Recuperado el 4 de septiembre de 2019 de: https://www.lanacion.com.ar/opinion/historia-en-dos-ciudadesnid830551.

Throsby, D. (2001). Economía y Cultura. Madrid, España: Cambridge University Press.

Unesco. (4 de noviembre de 1966). Declaración de los Principios de la Cooperación Cultural Internacional. París, Francia. Recuperado el 10 de septiembre de 2019 de:

http://portal.unesco.org/es/ev.phpURL ID=13147\&URL DO=DO TOPIC\&URL SECTION=201. $\underline{\mathrm{html}}$ 